PACS: $61.41 .+\mathrm{e}, 62.20 . \mathrm{fg}$

\title{
LOW TEMPERATURE DEFORMATION AND STRENGTH OF POLYIMIDE FILMS DUE TO THICKNESS AND DEFORMATION SPEED
}

\author{
V.A. Lototskaya ${ }^{1}$, L.F. Yakovenko ${ }^{1}$, E.N. Aleksenko ${ }^{1}$, V.V. Abraimov ${ }^{1}$, Wen Zhu Shao ${ }^{2}$ \\ ${ }^{I} B$. Verkin Institute for Low Temperature Physics and Engineering of NAS of Ukraine \\ Nauky av., 47, Kharkov, 61103, Ukraine \\ e-mail: lototskaya@ilt.kharkov.ua \\ ${ }^{2}$ Harbin Institute of Technology \\ Harbin, the People's Republic of China \\ Received April 20, 2017
}

In work mechanical properties of polyimide films analogue kapton $\mathrm{H}$ (manufactures of the People's Republic of China) with different thickness in the temperature interval 77-293 K and deformation speed interval $10^{-4}-10^{-3} \mathrm{~s}^{-1}$ are carried out. It is established, that the films are in a forced elastic state at both temperatures of deformation. Contributions to total deformation such as elastic, high elastic (reversible at temperature of test and delay) and irreversible components are determined. It is detected, that relaxation processes which are connected with the contribution of elastic delayed deformation and are accompanied with reduction of their length, take course at exposure at a room temperature of samples after destruction or preliminary deformation. Full removal high elastic delayed deformation occurs after heat treatment at $623 \mathrm{~K}$. Sensitivity of a limit of forced elasticity $\mathrm{s}_{\mathrm{B}}$ and the contribution of elastic deformation which is reversible at test temperature to deformation speed are established. Influence of the scale factor (thickness of a film) on the mechanical characteristics, which are amplified with downturn of temperature is registered.

KEY WORDS: polyimides, limit of forced elasticity, ultimate strength, deformability

\section{НИЗКОТЕМПЕРАТУРНАЯ ДЕФОРМАЦИЯ И ПРОЧНОСТЬ ПОЛИИМИДНЫХ ПЛЕНОК В ЗАВИСИМОСТИ ОТ ТОЛЩИНЫ И СКОРОСТИ ДЕФОРМИРОВАНИЯ \\ В.А. Лотоцкая ${ }^{1}$, Л.Ф. Яковенко ${ }^{1}$, Е.Н. Алексенко ${ }^{1}$, В.В. Абраимов ${ }^{2}$, Wen Zhu Shao ${ }^{2}$ \\ ${ }^{I}$ Физико-технический институт низких температур им. Б.И. Веркина НАН Украины \\ пр. Науки, 47, г. Харьков, 61103, Украина \\ 2 Харбинский Политехнический институт \\ 2. Харбин, КНР}

В работе изучены механические свойства (предел вынужденной эластичности, продел прочности и суммарная деформация до разрушения) полиимидных пленок типа kapton Н (производства КНР) разной толщины в интервале скоростей деформации $10^{-4}-10^{-3} \mathrm{c}^{-1}$ при температурах 77 и $293 \mathrm{~K}$. Установлено, что пленки при обеих температурах деформации находятся в вынуждено-эластическом состоянии. Определены вклады в суммарную деформацию упругой, высокоэластической (обратимой при температуре испытания и задержанной), и необратимой составляющих. При выдержке образцов после разрушения или предварительной деформации при комнатной температуре обнаружено протекание релаксационных процессов, связанных с вкладом задержанной эластической деформации, сопровождающееся сокращением их длины. Полное снятие задержанной эластической деформации происходит после отжига при 623 К. Установлена чувствительность предела вынужденной эластичности $\sigma_{\text {в }}$ и вклада обратимой при температуре испытания эластической деформации к скорости деформации. Зарегистрировано влияние масштабного фактора (толщины пленки) на механические характеристики, усиливающееся с понижением температуры.

КЛЮЧЕВЫЕ СЛОВА: полиимиды, предел вынужденной эластичности, предел прочности, деформируемость

\author{
НИЗЬКОТЕМПЕРАТУРНА ДЕФОРМАЦІЯ І МІЦНІСЬ ПОЛІМІДНИХ ПЛІВОК ЗАЛЕЖНО ВІД ТОВЩИНИ ТА \\ ШВИДКОСТІ ДЕФОРМУВАННЯ
В.О. Лотоцька ${ }^{1}$, Л.Ф. Яковенко ${ }^{1}$, С.М. Алексенко ${ }^{1}$ В.В. Абраімов ${ }^{2}$, Wen Zhu Shao \\ ${ }^{l}$ Фізико-технічний інститут низьких температур ім. Б.І. Веркіна НАН Украӥни \\ пр. Науки, 47, м. Харків, 61103, Україна \\ ${ }^{2}$ Харбінський Політехнічний інститут \\ м. Харбін, КНР
}

У роботі вивчені механічні властивості поліімідних плівок типу kapton Н (виробництва КНР) різної товщини в інтервалі швидкостей деформації $10^{-4}-10^{-3} \mathrm{c}^{-1}$ при температурах 77 та 293 К. Установлено, що плівки при обох температурах деформації перебувають у вимушено еластичному стані. Визначені внески в сумарну деформацію пружної, високоеластичної (оборотної при температурі випробування та затриманої) і необоротної складових. При витримуванні зразків після руйнування або попередньої деформації при кімнатній температурі виявлено протікання релаксаційних процесів, пов'язаних з внеском вимушеної еластичної деформації, що супроводжується скороченням їх довжини. Повне зняття вимушеної еластичної деформації відбувається після відпала при 623 К. Установлена чутливість границі вимушеної еластичності $\sigma_{\text {y }}$ і внеску оборотної при температурі випробування еластичної деформації до швидкості деформації. Зареєстрований вплив масштабного фактора (товщини плівки) на механічні характеристики, що підсилюється зі зниженням температури.

КЛЮЧОВІ СЛОВА: полііміди, границя змушеної еластичності, межа міцності, деформованість 
За последние 30 лет одной из основных тенденций в области создания космических аппаратов (КА) нового поколения является увеличение, приблизительно на 30\%, применения полимерных материалов в элементах конструкций КА и аппаратуре. При этом вследствие возрастания доли КА, осуществляющих длительные миссии в пределах солнечной системы, расширяется диапазон температур, при которых они эксплуатируются.

Наибольшее применение в аэрокосмической технике США, России, ЕС и КНР находят полимеры из класса полиимидов благодаря удачному сочетанию целого ряда физических свойств, обеспечивающих требуемые эксплуатационные характеристики. Полиимидные материалы, по сравнению с другими полимерами, обладают высокой термо- и радиационной стойкостью, хорошими диэлектрическими свойствами, высокой прочностью и деформируемостью в интервале температур $\sim 150 \div 500$ К. Вместе с тем, исследования механических характеристик полиимидных материалов в области низких температур в настоящее время еще не носят систематического характера. Полиимидные материалы, на которых изучали влияние низких температур на механические свойства, в большинстве своем не были сопоставимы не только по химическому строению, но и по технологии получения и геометрическим параметрам, что затрудняет детальное сравнение этих результатов [1-9].

Целью настоящей работы является исследование закономерностей деформации и прочности двух полиимидных пленок разной толщины, характеризующихся одной химической формулой полимера и изготовленных по одной технологии при температурах 293 К и 77 К. Метод механических испытаний одноосное растяжение в интервале скоростей деформации $10^{-4}-10^{-3} \mathrm{c}^{-1}$.

\section{МАТЕРИАЛ И МЕТОДИКА ИССЛЕДОВАНИЯ}

Объектом исследования являлись термопластичные пленки ароматического полиимида - поли -4,4'дифиниленоксидпиромеллитимида - производства КНР (аналог пленки ПМ-А производства России и kapton H производства США) толщиной 75 и 125 мкм. Строение мономера представлено структурной формулой

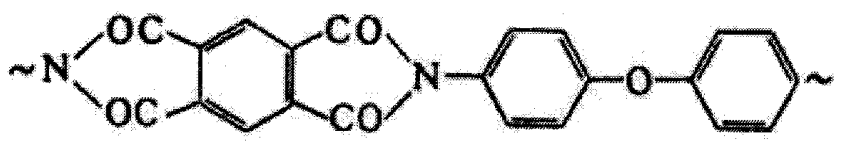

Образцы для испытания полиимидных пленок при одноосном растяжении (рис.1) получали с помощью специального штампа. Ось растяжения совпадала с направлением протяжки пленки. Форма и размеры образца близки образцу типа 1 по ГОСТ 11262-80, который допускается к использованию для испытаний на растяжение пленочных полимерных образцов (ГОСТ 14236-81). Крепление образца осуществляется в специальных захватах. Захват состоит из ролика, вокруг которого огибается лопатка образца и двух прижимов, захватывающих ролик с лопаткой.

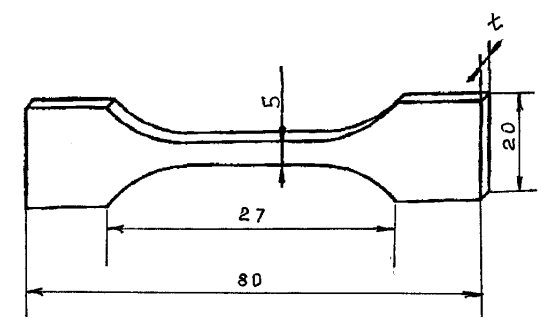

Рис.1. Форма образца (толщина образца $\mathrm{t}-75$ мкм или 125 мкм).

Деформирование образцов на воздухе (293 К) и в жидком азоте (77 К) в условиях одноосного растяжения проводили на разрывной машине FPZ-100/1 в специальных захватах при трех скоростях перемещения активного штока $\mathrm{V}_{\text {деф}}=0,85 ; 4,6$ и 7,6 мм/мин и, соответственно, при скоростях деформирования $\dot{\varepsilon}=7 \cdot 10^{-4}$;

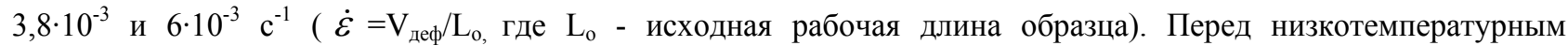
испытанием образец, находящийся в деформирующем устройстве, выдерживался в криостате с жидким азотом не менее 30 мин.

В процессе деформирования записывали диаграмму растяжения в координатах «нагрузка Р- удлинение $\Delta \mathrm{L} »$, из которой определяли следующие механические характеристики: условный предел вынужденной эластичности, соответствующий напряжению, при котором высокоэластическая деформация составляет $1 \%$, $\sigma_{\mathrm{B}}=\mathrm{P}_{1 \%} / \mathrm{S}_{\mathrm{o}}$; предел прочности (напряжение разрыва образца) $\sigma_{\mathrm{p}}=\mathrm{P}_{\mathrm{p}} / \mathrm{S}_{\mathrm{o}}$, где $\mathrm{S}_{\mathrm{o}}$ - начальное сечение образца; общее

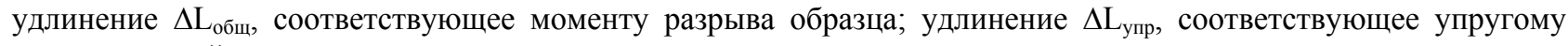
участку кривой.

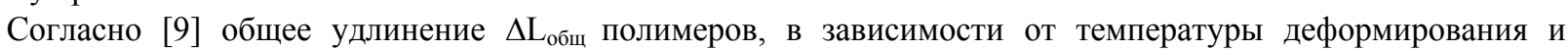
структурного состояния, может включать в себя несколько различных вкладов: обратимое (упругое) удлинение

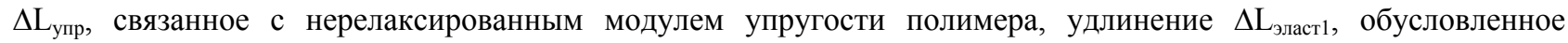

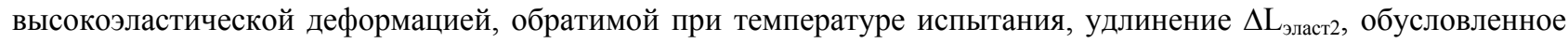




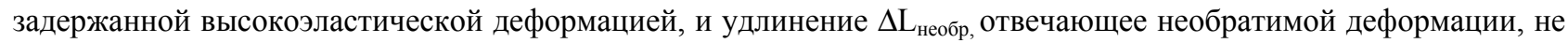
исчезающей при нагревании вплоть до температуры плавления $\mathrm{T}_{\text {пл }}$. Таким образом

$$
\Delta \mathrm{L}_{\text {общ }}=\Delta \mathrm{L}_{\text {упр }}+\Delta \mathrm{L}_{\text {эласт1 }}+\Delta \mathrm{L}_{\text {эласт } 2}+\Delta \mathrm{L}_{\text {необр. }} .
$$

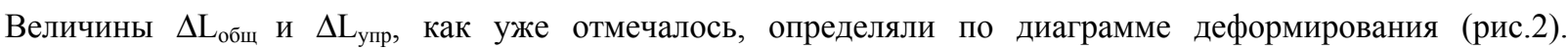
Остальные вклады, схематически представленные на рис.2 на разных участках диаграммы, измеряли по изменению длины рабочей части образца после деформации. Перед испытанием на рабочей части образца вблизи галтелей ${ }^{1}$ наносились реперные линии, расстояние между которыми (величину исходной рабочей длины образца $\mathrm{L}_{\mathrm{o}}$ и конечную длину после испытания $\mathrm{L}_{\mathrm{\kappa}}$ ) измеряли на компараторе ИЗА-2 с точностью до \pm 1 мкм. Величину $\Delta \mathrm{L}$ под нагрузкой и сразу после снятия нагрузки при температуре деформации измеряли катетометром КМ-2 с той же точностью. На образцах, деформированных при комнатной температуре, был

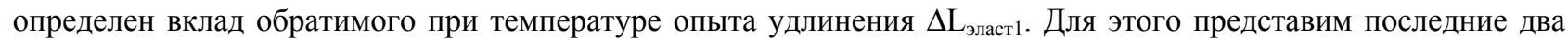
вклада в формуле (1) как остаточное удлинение, величина которого $\Delta \mathrm{L}_{\text {ост }}=\Delta \mathrm{L}_{\text {эласт2 }}+\Delta \mathrm{L}_{\text {необр }}=\left(\mathrm{L}_{\text {к }}-\mathrm{L}_{\text {о }}\right)$. Величину высокоэластического удлинения $\Delta \mathrm{L}_{\text {эласт1 }}$ определяли из соотношения (1). Нормируя полученные значения $\Delta \mathrm{L}_{\text {общ}}, \Delta \mathrm{L}_{\text {упр, }}, \Delta \mathrm{L}_{\text {ост }}$ и $\Delta \mathrm{L}_{\text {эласт }}$ на величину исходной рабочей длины образца $\mathrm{L}_{0}$, получали соответствующие значения относительной деформации $\varepsilon_{\text {общ }}, \varepsilon_{\text {упр }}, \varepsilon_{\text {ост }}$ и $\varepsilon_{\text {эласт1 }}$.

Для определения вклада истинной необратимой деформации и общей величины высокоэластической деформации $\left(\varepsilon_{\text {эласт1 }}+\varepsilon_{\text {эласт2})}\right)$ образцы, деформированные до разрушения при обеих температурах, были термообработаны при $623 \mathrm{~K}\left(350^{\circ} \mathrm{C}\right)$ в течение 2 час на воздухе. Согласно [9] нагрев до этой температуры, находящейся вблизи верхней границы работоспособности - температуры размягчения полимера $\mathrm{T}_{\mathrm{p}}=650 \mathrm{~K}$,

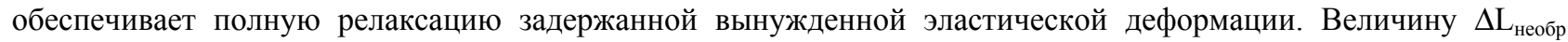
определяли по разности расстояния между реперными линиями после испытания и отжига и в исходном состоянии $\left(\mathrm{L}_{\text {отж}}-\mathrm{L}_{\mathrm{o}}\right)$.

Все указанные механические характеристики представлены далее как средние значения по результатам испытаний 2-4-х образцов.

\section{РЕЗУЛЬТАТЫ И ИХ ОБСУЖДЕНИЕ}

На рис. 3 представлены типичные диаграммы растяжения образцов полиимидной пленки разной толщины в координатах «напряжение - деформация» при температурах 293 и 77 К и скорости деформации $7 \cdot 10^{-4} \mathrm{c}^{-1}$.

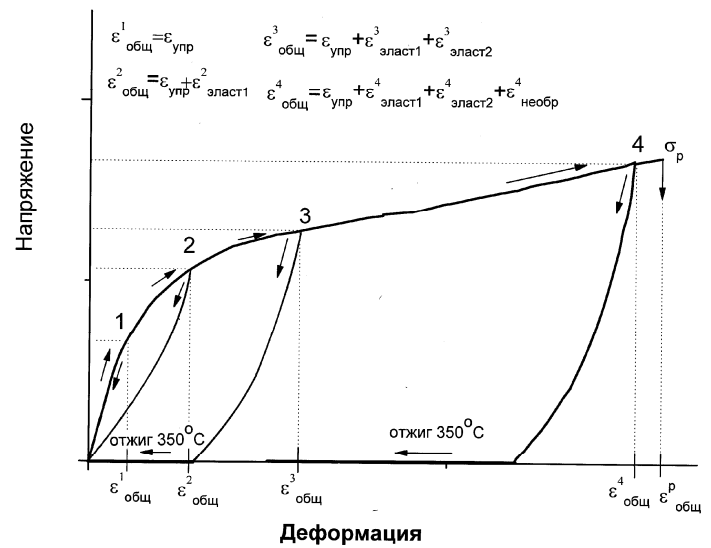

Рис.2. Деформационная кривая при нагружении и разгрузке полиимидной пленки толщиной 75 мкм, деформированной при скорости деформации $7 \cdot 10^{-4} \mathrm{c}^{-1}$ до некоторых нагрузок $(1,2,3,4)$ при $293 \mathrm{~K}$

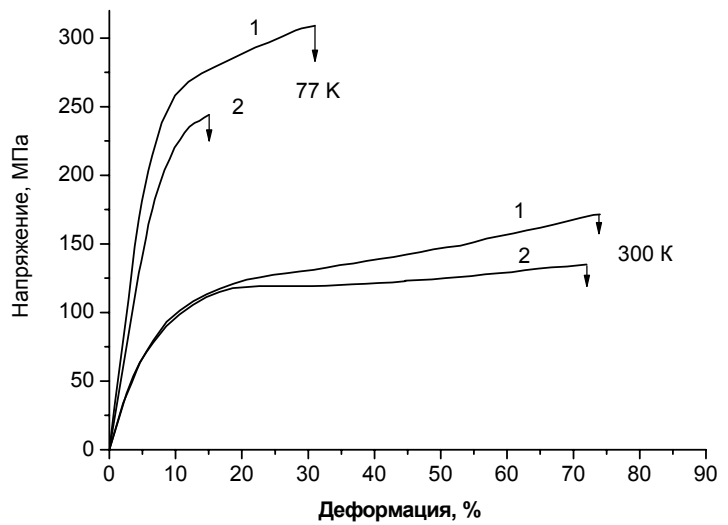

Рис.3. Типичные кривые растяжения полиимидной пленки толщиной 75 мкм (1) и 125 мкм (2) при различных температурах и скорости деформации $7 \cdot 10^{-4} \mathrm{c}^{-1}$

Взаимное расположение этих диаграмм и их характер не зависят от скорости растяжения образцов. Все диаграммы растяжения содержат две стадии - линейную и нелинейную. Для выяснения деталей процесса деформирования пленок в этих условиях несколько образцов были нагружены в пределах линейной и нелинейной стадий диаграммы и затем разгружены (рис.2). При нагружении ниже напряжения отклонения от линейности на кривой $(\sigma-\varepsilon)(1$, рис.2) при обеих температурах пленки испытывают только упругую деформацию и диаграммы при нагружении и разгрузке совпадают. После нагружения образца на начальный участок второй нелинейной стадии (2, рис.2) при последующей разгрузке до $\sigma=0$ наблюдается гистерезис хода кривой $(\sigma-\varepsilon)$. При этом вся деформация, запасенная в образце, при разгрузке продолжает оставаться полностью обратимой. При дальнейшем нагружении вплоть до $\sigma \sim 90 \% \sigma_{p}(3,4$, рис.2) гистерезис хода кривой

\footnotetext{
${ }^{1}$ Реперные линии наносились гелем без нарушения целостности поверхности пленки.
} 
при разгрузке продолжает наблюдаться, но обратимой при температуре эксперимента остается часть запасенной деформации. Аналогичным образом ведут себя образцы, деформированные до этих величин нагрузки при 77 К. Пленки при обеих температурах деформации, таким образом, находятся в области вынужденной эластичности.

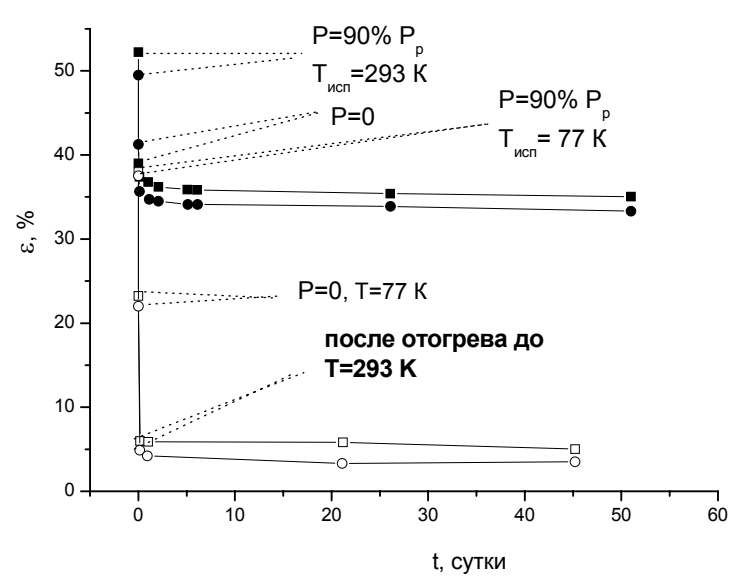

a

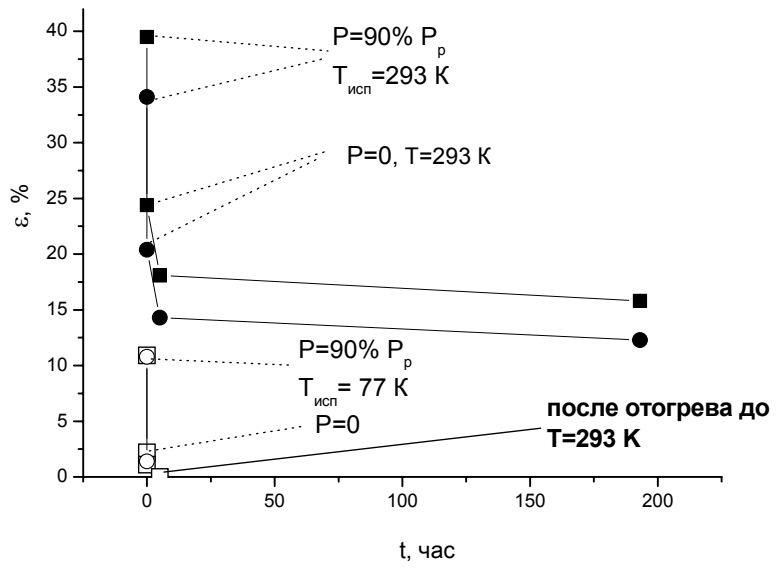

6

Рис.4. Зависимости остаточной деформации образцов пленок толщиной 75 мкм (а) и 125 мкм (б), деформированных при 293 К и 77 К, от времени выдержки при комнатной температуре

Для выяснения природы остаточной деформации на пленках, деформированных при обеих температурах испытания, после разгрузки были проведены эксперименты по измерению изменения величины остаточной деформации образцов от времени выдержки при комнатной температуре (рис.4 а,б). Было обнаружено, что пленки обеих толщин, деформированные как при 293, так и при 77К, находятся в неравновесном состоянии, в них протекают релаксационные процессы и длина рабочей части сокращается. Релаксационные процессы можно разделить на две группы. К первой группе относятся процессы, протекающие быстро, в течение первых часов, ко второй - развивающиеся медленно и продолжающиеся даже после выдержки более 60 суток, т.е. часть остаточной деформации можно рассматривать как задержанную высокоэластическую. После деформации пленок при Т $=77$ К часть задержанной после разгрузки вынужденной эластической деформации релаксирует уже при отогреве до комнатной температуры, что согласуется с данными, приведенными в [8]. При этом в образцах пленки толщиной 75 мкм медленные релаксационные процессы продолжаются при комнатной температуре, а в образцах пленки толщиной 125 мкм остаточная деформация после отогрева близка к нулю. Т.о., использовать измерение остаточного удлинения при комнатной температуре для вычисления величины $\Delta \mathrm{L}_{\text {эласт1 }}$, отвечающей быстрым релаксационным процессам, можно только для образцов, деформированных до разрушения при 293 К, а для образцов, деформированных при 77 К, некорректно. Величины задержанной вынужденной эластической деформации были, как указано в методике, определены после отжига вблизи Т.

На рис. 5 представлены зависимости средних значений условного предела вынужденной эластичности $\sigma_{\mathrm{B}}$,

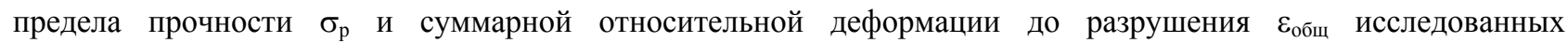
полиимидных пленок от температуры и скорости деформации.

Из рис.5 видно, что исследуемые пленки проявляют сильную температурную зависимость механических

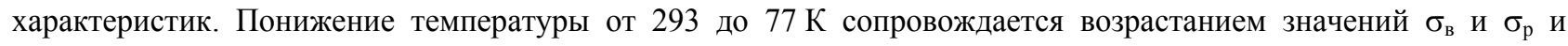

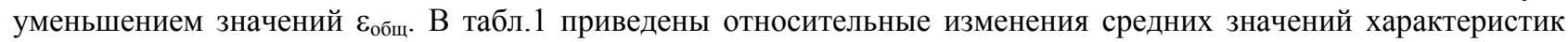
прочности и деформации при температурах 293 и 77 К. Видно, что основной вклад в повышение прочностных характеристик при понижении температуры вносит рост предела вынужденной эластичности.

Возрастание скорости деформации (рис.5) полиимидных пленок почти на порядок как при 293 К, так и при

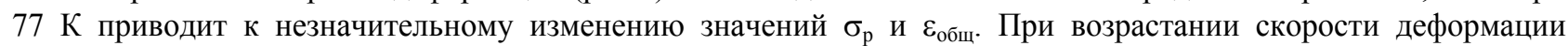

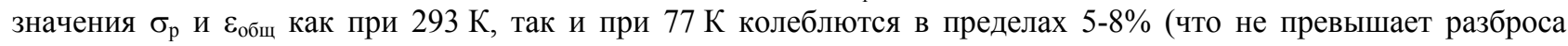

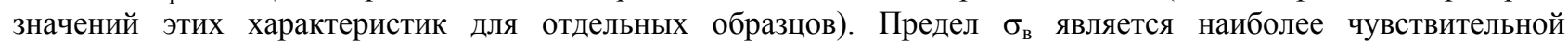
характеристикой, его значения демонстрируют устойчивое увеличение до 25-30\% при 293 К для обеих пленок и до 17\% при 77 К для более толстой пленки.

Степень влияния масштабного фактора (толщины пленки) на механические характеристики изменяется с понижением температуры (рис.5). Так, при 293 К увеличение толщины пленки влияет, в основном, на $\sigma_{\mathrm{p}}$,

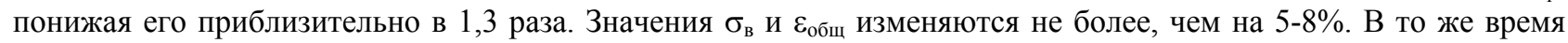
при $77 \mathrm{~K}$ уже все изучаемые характеристики пленки толщиной 125 мкм заметно снижают свои значения по

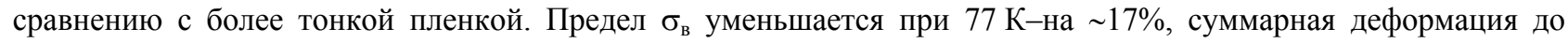

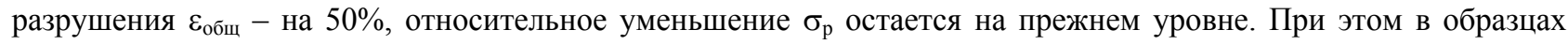
более толстой пленки отношение $\sigma_{\mathrm{B}} / \sigma_{\mathrm{p}}$ при обеих температурах выше и имеет заметную скоростную 
чувствительность (табл.1). При $77 \mathrm{~K}$ и скорости деформации $\dot{\varepsilon}_{3}=6 \cdot 10^{-3} \mathrm{c}^{-1}$ отношение $\sigma_{\mathrm{B}} / \sigma_{\mathrm{p}}$ в пленке толщиной 125 мкм достигает 81\%. Известно[10, 11], что полимер начинает разрушаться хрупко без заметной предварительной деформации, если предел вынужденной эластичности сравнивается с пределом прочности. Тогда наши данные свидетельствуют, что пленка толщиной 125 мкм должна достигнуть температуры хрупкости $\mathrm{T}_{\mathrm{xp}}$ (нижней границы области вынужденной эластичности) при более высокой температуре, которая к тому же будет возрастать с повышением скорости деформации.
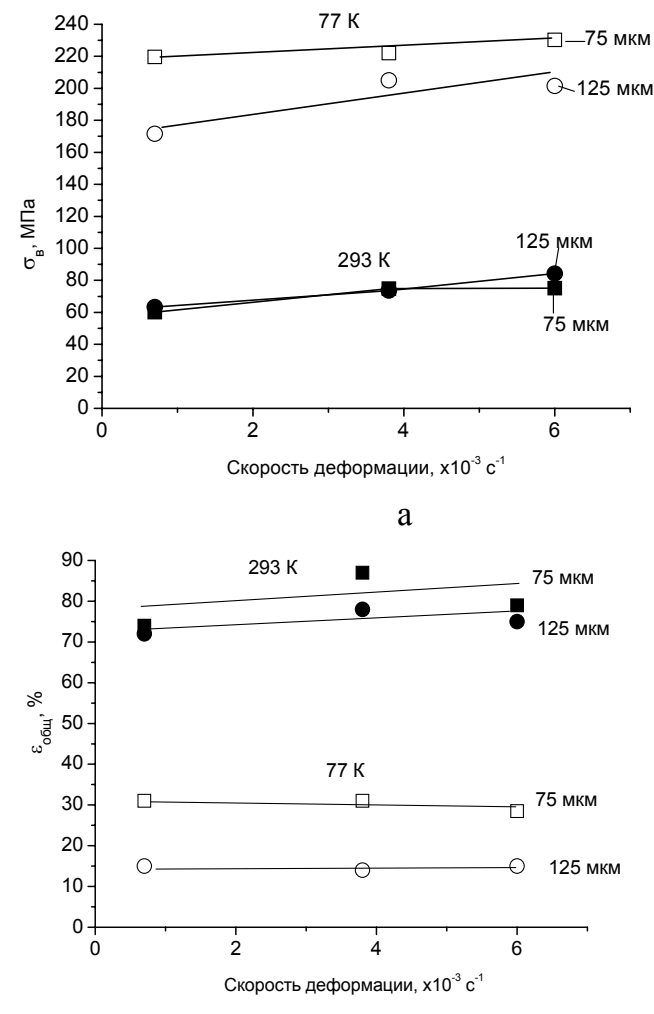

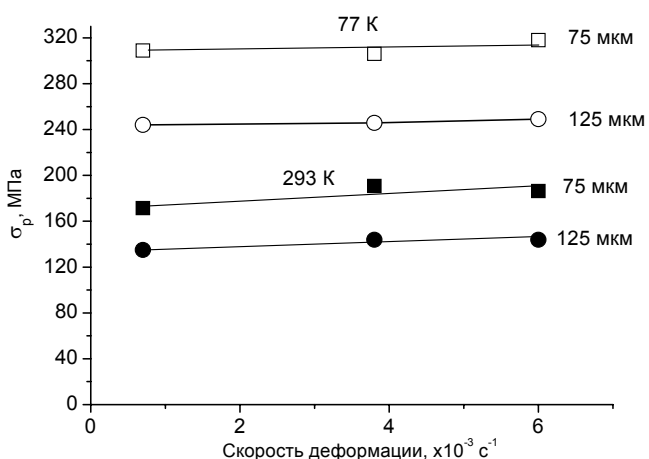

б

Рис. 5. Зависимости условного предела вынужденной эластичности $\sigma_{\mathrm{B}}(\mathrm{a})$, предела прочности $\sigma_{\mathrm{p}}($ б) и суммарной деформации $\varepsilon_{\text {общ }}$ (в) полиимидных пленок разной толщины при разных скоростях деформации и температурах 77 и $293 \mathrm{~K}$

Таблица 1

Относительное изменение средних значений характеристик прочности и деформируемости исследованных полиимидных пленок при 293 и $77 \mathrm{~K}$.

\begin{tabular}{|c|c|c|c|c|c|}
\hline $\begin{array}{c}\text { Толщина } \\
\text { пленки t, мкм }\end{array}$ & $\frac{\sigma_{6293 K}}{\sigma_{p 293 K}}$ & $\frac{\sigma_{\text {s } 77 K}}{\sigma_{p 77 \kappa}}$ & $\frac{\sigma_{677 K}}{\sigma_{6293 K}}$ & $\frac{\sigma_{p 77 K}}{\sigma_{p 293 K}}$ & $\frac{\mathcal{E}_{293 K}}{\mathcal{E}_{77 \kappa}}$ \\
\hline \multicolumn{6}{|c|}{$\dot{\varepsilon}_{I}=7 \cdot 10^{-4} \mathrm{c}^{-1}$} \\
\hline 75 & 0,35 & 0,71 & 3,7 & 1,8 & 2,4 \\
\hline 125 & 0,47 & 0,71 & 2,7 & 1,8 & 4,8 \\
\hline \multicolumn{6}{|c|}{$\dot{\varepsilon}_{2}=3,8 \cdot 10^{-3} \mathrm{c}^{-1}$} \\
\hline 75 & 0,39 & 0,73 & 3,0 & 1,6 & 2,8 \\
\hline 125 & 0,51 & 0,83 & 2,8 & 1,7 & 5,6 \\
\hline \multicolumn{6}{|c|}{$\dot{\varepsilon}_{3}=6 \cdot 10^{-3} \mathrm{c}^{-1}$} \\
\hline 75 & 0,4 & 0,72 & 3,1 & 1,7 & 2,8 \\
\hline 125 & 0,58 & 0,81 & 2,4 & 1,7 & 5,0 \\
\hline
\end{tabular}

Теперь рассмотрим влияние понижения температуры и увеличения скорости деформации на

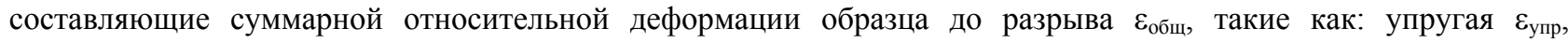
высокоэластическая деформация $\varepsilon_{\text {эласт1 }}$, обратимая при температуре испытания (T=293 К), полная вынужденная

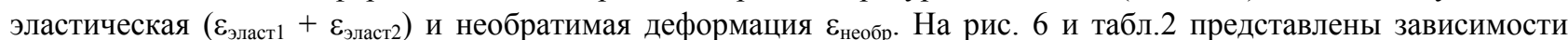
средних значений этих характеристик от температуры и скорости деформации. В табл. 3 для трех скоростей

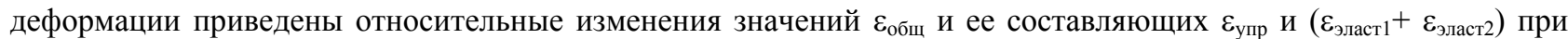

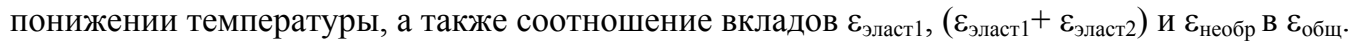

Анализируя приведенные результаты, следует отметить, что при обеих температурах испытания основной

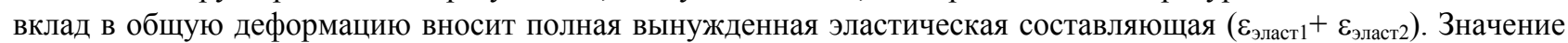

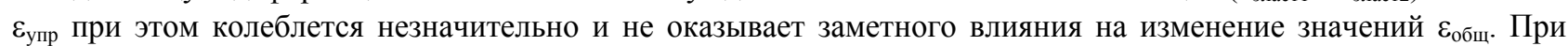




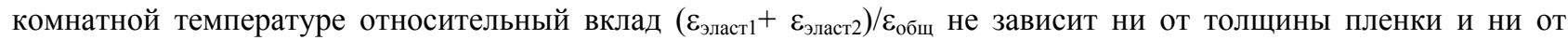
скорости деформации (табл.3), что согласуется с данными [12]. Однако вклад деформации, обратимой при

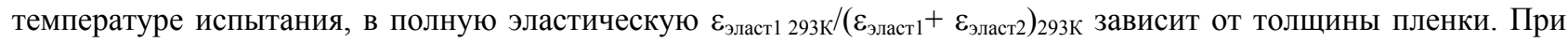
этом, если в пленке толщиной 75 мкм уменьшение данной величины со скоростью деформации слабое и может трактоваться как случайное, то в пленке толщиной 125 мкм величина этого вклада достаточно существенно зависит от скорости деформации и резко уменьшается с ее увеличением.

При комнатной температуре в обеих пленках наблюдается также необратимая деформация, сохраняющаяся вплоть до $\mathrm{T}_{\mathrm{p}}$, которая может быть связана либо с пластическими, либо с вязко-текучими процессами при нагружении. Вклад необратимой деформации в общую деформацию не зависит ни от скорости, ни от толщины пленки.

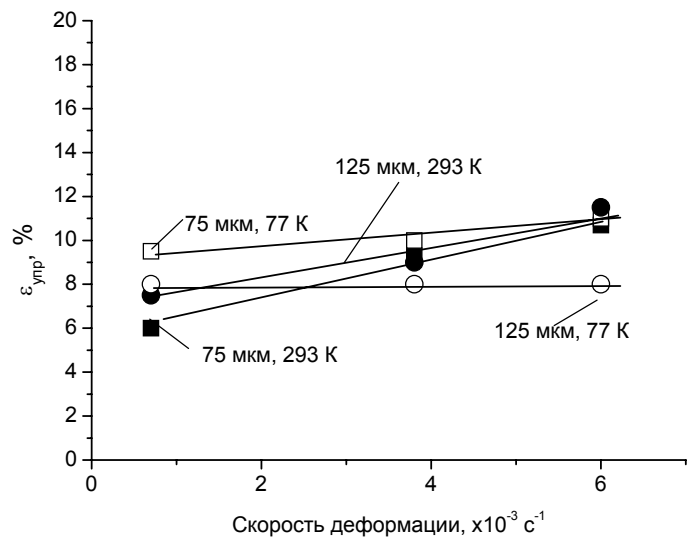

a

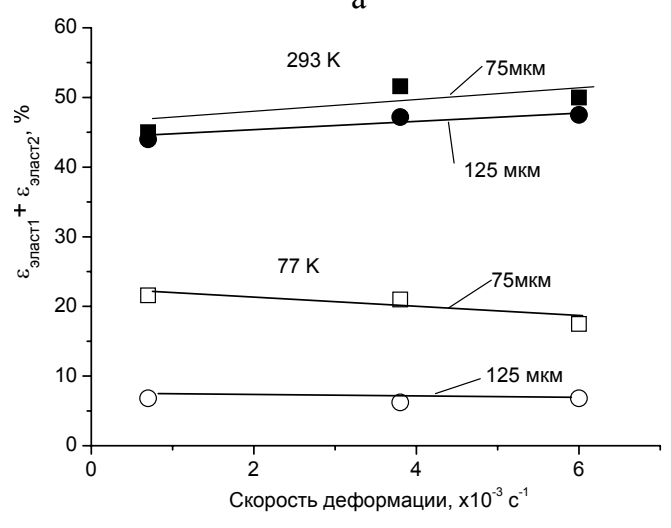

B

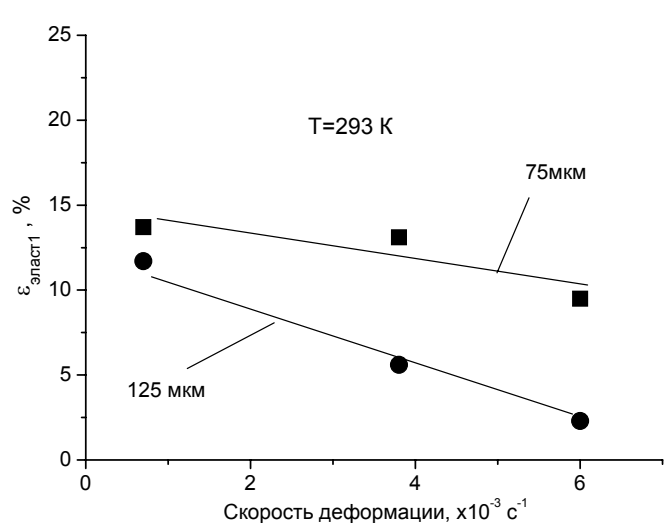

6

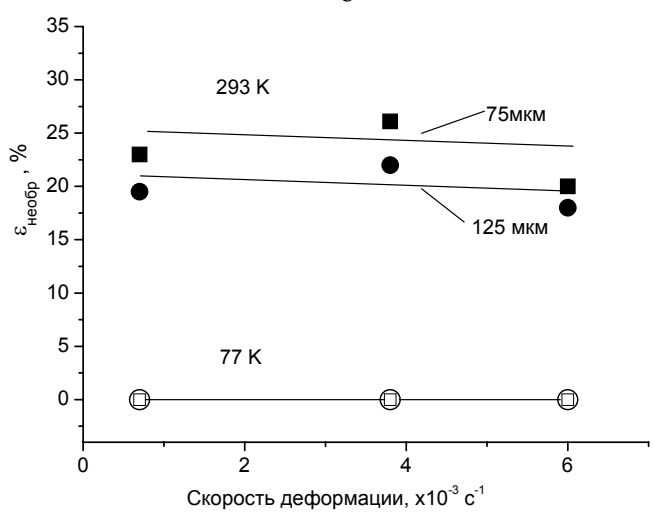

$\Gamma$

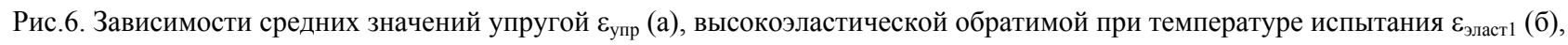
полной высокоэластической $\left(\varepsilon_{\text {эласт1 }}+\varepsilon_{\text {эласт2 }}\right)\left(\right.$ в) и необратимой деформации $\varepsilon_{\text {необр }}(г)$ полиимидных пленок разной толщины от скорости деформации при температурах 77 и 293 К

При 77 К величины суммарной и полной вынужденной эластической деформаций снижаются в несколько

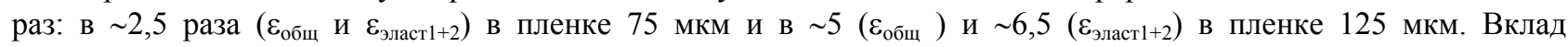
необратимой деформации отсутствует в обеих пленках. Вся остаточная деформация, наблюдаемая при отогреве до комнатной температуры, оказывается задержанной эластической (исчезает после отжига при 623 К). Поскольку общая деформация до разрушения при $77 \mathrm{~K}$ существенно ниже $\left(\varepsilon_{\text {общ }}=31 \%, 75\right.$ мкм и $\varepsilon_{\text {общ }}=15 \%$, 125 мкм), чем при 293 К, а необратимая деформация начинает происходить на нелинейной стадии после значительного участка полностью обратимой деформации, то, вполне вероятно, что при 77 К этот уровень деформаций уже не достигается. Для проверки образцы обеих пленок были продеформированы при комнатной температуре до величин суммарной деформации, соответствующих суммарной деформации до разрушения при $77 К$, и затем проведен отжиг при $350^{\circ} \mathrm{C}$. Установлено, что при этих степенях деформации как при 77 К, так и при 293 К суммарная деформация включает, кроме упругой, только высокоэластическую деформацию, что согласуется с результатами [12]. Важно отметить, что при этом относительный вклад полной эластической деформации $\varepsilon_{\text {эласт1+2 }} / \varepsilon_{\text {общ }}$ в пленке толщиной 75 мкм при всех скоростях деформации сохраняется на том же уровне $\sim 0,6$, что и при комнатной температуре в обеих пленках, а в пленке толщиной 125 мкм он понижается до 0,45. Скоростная чувствительность вклада полной эластической деформации при 77К, так же как и при 293 К отсутствует. 
Таблица 2

Средние значения суммарной относительной деформации до разрыва $\varepsilon_{\text {общ }}$ и ее составляющих исследованных полиимидных пленок при температурах 77 и $293 \mathrm{~K}$

\begin{tabular}{|c|c|c|c|c|c|c|}
\hline $\begin{array}{c}\text { Толщина } \\
\text { пленки t, мкм }\end{array}$ & $\begin{array}{c}\mathrm{T}, \\
\mathrm{K}\end{array}$ & 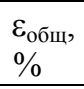 & $\begin{array}{l}\begin{array}{l}\varepsilon_{\text {упр }}, \\
\%\end{array} \\
\end{array}$ & $\begin{array}{c}\varepsilon_{\text {эласт1 }}, \\
\% \\
\end{array}$ & $\begin{array}{c}\varepsilon_{\text {эл } 1}+\varepsilon_{\text {эл } 2}, \\
\% \\
\end{array}$ & $\begin{array}{c}\varepsilon_{\text {необр }}, \\
\%\end{array}$ \\
\hline \multicolumn{7}{|c|}{$\dot{\varepsilon}_{l}=7 \cdot 10^{-4} \mathrm{c}^{-1}$} \\
\hline $\begin{array}{c}75 \\
125\end{array}$ & 293 & $\begin{array}{l}74 \\
72\end{array}$ & $\begin{array}{l}6,5 \\
7,5\end{array}$ & $\begin{array}{c}13,7 \\
11\end{array}$ & $\begin{array}{l}45 \\
44\end{array}$ & $\begin{array}{l}22,5 \\
20,5\end{array}$ \\
\hline $\begin{array}{l}75 \\
125\end{array}$ & 77 & $\begin{array}{l}31 \\
15\end{array}$ & $\begin{array}{l}9,5 \\
8,0\end{array}$ & & $\begin{array}{c}21,6 \\
6,8\end{array}$ & $\begin{array}{l}0 \\
0\end{array}$ \\
\hline \multicolumn{7}{|c|}{$\dot{\varepsilon}_{2}=3,8 \cdot 10^{-3} \mathrm{c}^{-1}$} \\
\hline $\begin{array}{c}75 \\
125 \\
\end{array}$ & 293 & $\begin{array}{l}87 \\
78 \\
\end{array}$ & $\begin{array}{l}9,5 \\
8,0 \\
\end{array}$ & $\begin{array}{c}13,0 \\
5,5\end{array}$ & $\begin{array}{l}51,4 \\
47,2 \\
\end{array}$ & $\begin{array}{l}26,1 \\
22,8 \\
\end{array}$ \\
\hline $\begin{array}{c}75 \\
125 \\
\end{array}$ & 77 & $\begin{array}{l}31 \\
14 \\
\end{array}$ & $\begin{array}{c}10,0 \\
8,0 \\
\end{array}$ & & $\begin{array}{l}21 \\
6,2 \\
\end{array}$ & $\begin{array}{l}0 \\
0 \\
\end{array}$ \\
\hline \multicolumn{7}{|c|}{$\dot{\varepsilon}_{3}=6 \cdot 10^{-3} \mathrm{c}^{-1}$} \\
\hline $\begin{array}{c}75 \\
125\end{array}$ & 293 & $\begin{array}{l}79 \\
75\end{array}$ & $\begin{array}{l}11,0 \\
11,0\end{array}$ & $\begin{array}{l}9,5 \\
2,5\end{array}$ & $\begin{array}{l}48 \\
46\end{array}$ & $\begin{array}{l}20 \\
18\end{array}$ \\
\hline $\begin{array}{c}75 \\
125\end{array}$ & 77 & $\begin{array}{c}28,5 \\
15\end{array}$ & $\begin{array}{c}11,0 \\
8,0\end{array}$ & & $\begin{array}{c}17,5 \\
6,9\end{array}$ & $\begin{array}{l}0 \\
0\end{array}$ \\
\hline
\end{tabular}

Таблица 3

Соотношения средних значений суммарной относительной деформации и ее составляющих $\varepsilon_{\text {упр }}, \varepsilon_{\text {эласт }}$ и $\varepsilon_{\text {ост }}$ исследованных полиимидных пленок при температурах 77 и 293 К и разных скоростях деформации

\begin{tabular}{|c|c|c|c|c|c|c|c|}
\hline $\begin{array}{c}\text { Толщина } \\
\text { пленки t, } \\
\text { мкм }\end{array}$ & $\frac{\boldsymbol{\varepsilon}_{\text {оби } 293 K}}{\boldsymbol{E}_{\text {оби } 77 К}}$ & $\frac{\mathcal{E}_{\text {ynp } 293 K}}{\mathcal{E}_{\text {ynp } 77 K}}$ & $\frac{\boldsymbol{\varepsilon}_{\text {эласт }(1+2) 293 K}}{\boldsymbol{E}_{\text {эласт }(1+2) 77 К}}$ & $\frac{\boldsymbol{E}_{\text {эласт(1)293К }}}{\boldsymbol{E}_{\text {эласт(1+2)293K }}}$ & $\frac{\mathcal{E}_{\text {эласт }(1+2) 293 K}}{\mathcal{E}_{\text {оби } 293 K}}$ & $\frac{\boldsymbol{E}_{\text {эласт }(1+2) 77 K}}{\boldsymbol{E}_{\text {оби } 77 K}}$ & $\frac{\mathcal{E}_{\text {необр } 293 K}}{\boldsymbol{E}_{\text {оби } 293 K}}$ \\
\hline \multicolumn{8}{|c|}{$\dot{\varepsilon}_{l}=7 \cdot 10^{-4} \mathrm{c}^{-1}$} \\
\hline 75 & 2,4 & 0,7 & 2,1 & 0,3 & 0,61 & 0,7 & 0,3 \\
\hline 125 & 4,8 & 0,95 & 6,5 & 0,25 & 0,61 & 0,45 & 0,28 \\
\hline \multicolumn{8}{|c|}{$\dot{\varepsilon}_{2}=3,8 \cdot 10^{-3} \mathrm{c}^{-1}$} \\
\hline 75 & 2,8 & 0,95 & 2,5 & 0,25 & 0,59 & 0,68 & 0,3 \\
\hline 125 & 5,6 & 1,25 & 7,6 & 0,12 & 0,61 & 0,44 & 0,29 \\
\hline \multicolumn{8}{|c|}{$\dot{\varepsilon}_{3}=6 \cdot 10^{-3} \mathrm{c}^{-1}$} \\
\hline 75 & 2,8 & 1,0 & 2,7 & 0,2 & 0,61 & 0,61 & 0,25 \\
\hline 125 & 5,0 & 1,4 & 6,7 & 0,06 & 0,61 & 0,46 & 0,24 \\
\hline
\end{tabular}

Итак, в исследованном интервале скоростей деформации и температур механические характеристики пленок слабо зависят скорости деформации. Чувствительность к изменению скорости деформации обнаруживают только предел вынужденной эластичности и вклад обратимой при температуре опыта эластической деформации. Согласно [10, 11] скорость развития вынужденной эластической деформации (перегруппировки сегментов цепных молекул и целых молекулярных агрегатов под действием внешних сил) включает в себя комплекс релаксационных процессов, среди которых есть такие, времена релаксации которых сопоставимы с временем механического воздействия и соответственно их развитие зависит от скорости деформации. В нашем случае наличие группы процессов с малыми временами релаксации подтверждает характер зависимости удлинения деформированных образцов от времени выдержки после разгрузки.

Зависимость механических свойств от температуры сильная в обеих пленках. При этом влияние разной толщины пленок существенно проявляется при понижении температуры. При 77 К с увеличением толщины пленки увеличивается скорость релаксационных процессов при отогреве до комнатной температуры, уменьшается относительный вклад вынужденной эластической деформации в общую, возрастание предела $\sigma_{\text {в }} \mathrm{c}$ понижением температуры существенно отстает от такового в более тонкой пленке, но при этом отношение $\sigma_{\mathrm{B}} / \sigma_{\mathrm{p}} \rightarrow 1$ быстрее и имеет скоростную чувствительность. Такое поведение может быть обусловлено несколькими причинами. С одной стороны, согласно [10] влияние масштабного фактора связано просто с увеличением числа дефектов в более толстой пленке. Однако при комнатной температуре его влияние достаточно слабое. С другой, необходимо учесть, что при изменении толщины пленки [13] и охлаждении до низких температур [14] ранее наблюдалось изменение степени ориентационной перегруппировки гибких 
макромолекул полипиромеллитимида в сторону большей упорядоченности. Также возможно изменение механизмов, контролирующих деформацию пленок при низких температурах [9], что может по - разному влиять при различной степени упорядоченности структуры. Поэтому основной причиной различия механических свойств пленок при 77 К предполагается большая степень упорядоченности структуры при увеличении толщины пленки, что приводит к появлению более высоких энергетических барьеров при перестройке надмолекулярной структуры и сильнее проявляется при уменьшении термических флуктуаций. Для проверки гипотезы в дальнейшем будут проведены рентгеноструктурные исследования.

\section{ВЫВОДЫ}

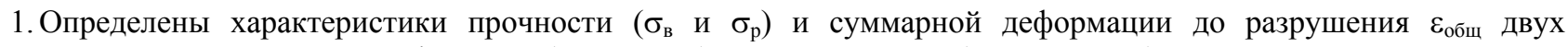
полиимидных пленок типа kapton Н (пр-ва КНР) разной толщины (75 и 125 мкм) при температурах 293 и 77 К в интервале скоростей деформации $10^{-4}-10^{-3} \mathrm{c}^{-1}$. Установлено, что механические характеристики исследованных полиимидных пленок имеют сильную температурную зависимость. При понижении температуры от 293 К до 77 К характеристики прочности возрастают, а величина деформации снижается.

2. Установлено, что кривые деформации имеют две стадии: линейную и нелинейную, а суммарная деформация

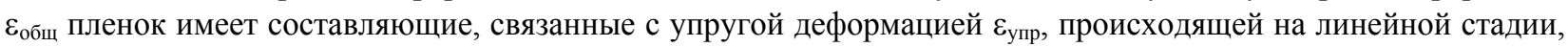

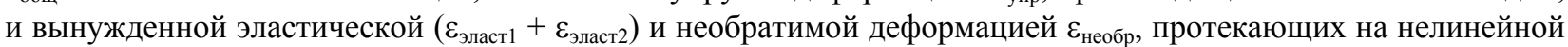
стадии. Полная вынужденная эластическая деформация состоит из высокоэластической деформации $\varepsilon_{\text {эласт1 }}$,

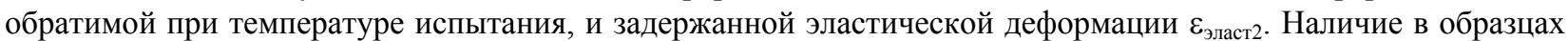
задержанной эластической деформации приводит к сокращению длины образцов при выдержке при 293К после разрушения или предварительной деформации. Полное снятие задержанной эластической деформации происходит после отжига при $623 \mathrm{~K}$.

3. Обнаружена скоростная чувствительность предела вынужденной эластичности $\sigma_{\text {в }}$ и вклада

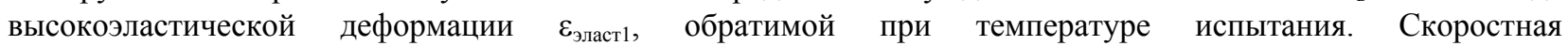
чувствительность предела прочности $\sigma_{\mathrm{p}}$, суммарной деформации $\varepsilon_{\text {общ }}$ и ее составляющих: упругой, полной эластической и необратимой деформации практически отсутствует.

4. Обнаружено влияние масштабного фактора (толщины пленки) на механические характеристики полиимидных пленок, усиливающееся с понижением температуры.

5. Увеличение влияния толщины пленки на механические характеристики при 77 К, повышение скоростной

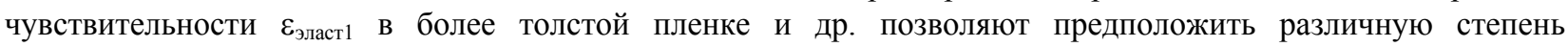
упорядочения молекулярной структуры исследованных пленок разной толщины.

Авторы признательны Лубенцу С.В. и Нацику В.Д. за прочтение текста статьи и ценные замечания, высказанные в процессе ее обсуждения.

\section{СПИСОК ЛИТЕРАТУРЫ}

1. Sorgolova T.I. Demina M.I. Temperaturnaya zavisimost' mehanicheskih svoystv polimerov razlichnogo himicheskogo stroeniya $\mathrm{v}$ intervale temperatur ot $4.2 \mathrm{~K}$ do $300 \mathrm{~K}$ [Temperature dependence of mechanical properties of polymers with various chemical structure in the temperature interval from 4,2 up to $300 \mathrm{~K}$ ] // Mechanika polimerov [Mechanics of Polymers].-1977.-No.3.-P.387-391 (in Russian).

2. A.David Grove Polyimide x-ray filter substrates optimized for cryogenic temperatures // Proc. SPIE 3766, X-Ray Optics, Instruments, and Missions II, 386 (September 29, 1999); doi:10.1117/12.363653 (http://www.luxel.com).

3. E. Tschegg, K. Humer and H.W. Weber Mechanical properties and fracture behaviour of polyimide (SINTIMID) at cryogenic temperatures // Cryogenics.- 1991.-Vol.31, October.-P.878 - 883.

4. Malay K.Ghosh, K.L.Mittal Polyimides Fundamentals and Applications, Marcel Dekker Inc., New York.-1996.

5. Abraimov V.V., Agashkova N.N., Bone L., Budnyak I.V., Velichko N.I., Krevsun A.V., Kostenko V.I., Lura F., Markus A.M. Kompleksnye issledovaniya fiziko-mechanicheskih svoystv materialov svetopogloshchayushchih pokrytiy kosmicheskih apparatov proektov "Mars-96" I "Regata" pod vozdeystviem factorov kosmicheskogo prostranstva [Complex researches of physico-mechanical properties of materials of light-absorbing coverings of space vehicles of projects «Mars -96» and "Regatta" under influence of space factors ] // Kosmichna nauka i technologiya [Space Science and Technology].-1995.-Vol.1, No.1.P.57-68 (in Russian).

6. Abraimov V.V., Lototskaya V.A., Saltevskiy G.I., Zaritskiy I.P Investigation of mechanical properties of polyimide materials in the $4.2-300 \mathrm{~K}$ temperatures interval // Conference Abstracts of $4^{\text {th }}$ Inter. Conf. "Space technologies; the present and the future", 17-19 April 2013.- Dnepropetrovsk.- Kyiv - P.88.

7. Abraimov V.V., Lototskaya V.A., Zaritskiy I.P. Investigation of peculiarities of mechanical properties of some polymeric materials in the 4.2-300 K temperatures interval // Conference Abstracts of $4^{\text {th }}$ Inter. Conf. "HighMatTech-2013", 7-11 October 2013.- Kyiv.- Ukraine.- P.278.

8. Soldatov V.P., Kirichenko G.I., Abraimov V.V., Braude I.S., Geidarov V.G. The laws of deformation of an amorphous polyimide (PI) film when it is stretched in the temperature range 1,6-300 K//Low Temperature Physics.-2016.- No.9.-P.10431052.

9. Bessonov M.I., Koton M.M., Kudryavtsev V.V., Layus L.A. Polyimidyu - klass termostoykih polymerov [Polyimides - class of heat-resistant polymers].-L.: Nauka.-1984.-328 p. (in Russian).

10. Bartenev G.M., Zuev Yu.S. Prochnost' I razrushenie vysokoelastichnyh materialov [Strength and rupture of highly elastic 
materials M.-L: Izd-vo «Himiyu», 1964.- 335 p. (in Russian).

11. Kargin V.A., Slonimskiy G.L. Kratkie ocherki po fiziko-chimii polymerov [Brief sketches in physics \& chemistry of polymers].-M.-L: Izd-vo «Himiyu», 1967.- 232 p. (in Russian).

12. Lur'e E.G., Kovriga V.V. K voprosu o edinstve mehanizma deformatsii I camoproizvol'nogo udlineniya jestkotsepnyh polymerov [To a question about unity of the deformation mechanism and spontaneous lengthening of rigidly chain polymers] // Mechanics of polymers.-1977.- No.4.-P.587-593 (in Russian).

13. Lur'e E.G., Kazaryan L.G., Uchastkina E. L., Kovriga V.V. Vlasova K.N., Dobrohotova M.L., Emel'yanova L.N. Struktura polypiromellitimida I ee vliyanie na fisiko-mehanicheskie cvoystva [Structure of polypiromellitimide and its influence on physico- mechanical properties] //Vysokomolekulyarnye coedineniya .-1974.-Vol.(A) XIII. - No.3. - P.603-607 (in Russian).

14. Braude I.S., Gal'tsov N.N., Geidarov V.G., Kirichenko G.I., Abraimov V.V. Effect of deformation and temperature on ordering of polyimide PM-A - molecules. X-ray data // Low Temperature Physics.-2016.- Vol.42. - No.3.- P.204-207. 